\title{
La información financiera y bancaria oficial y la última crisis económica (1999-2012). El caso del Banco de España
}

\author{
MARTín SEVILLA JiMÉNEZ ${ }^{\text {a }}$, TERESA TORREGROSA MARTí a , MARÍA NúÑEZ \\ ROMERO $^{\text {a }}$ \\ ${ }^{a}$ Universidad de Alicante, Fctd. CC.EE. y EE. Apto. Correos 99, 03080 Alicante, España. E- \\ mail:martin.sevilla@ua.es, teresa.torregrosa@ua.es, maria.romero@ua.es
}

\begin{abstract}
RESUMEN
La crisis económica y financiera que ha afectado durante los últimos años a gran parte de los países desarrollados presenta rasgos diferenciales muy acusados en cada uno de ellos. En el caso español, la gestación previa de la crisis vino impulsada por la introducción del euro y la Política Monetaria Europea aplicada por el Banco Central Europeo (BCE) que dieron la falsa sensación de que teníamos asegurada en el futuro la estabilidad monetaria con bajos tipos de interés. Este proceso necesitaba de unos agentes que posibilitaran el apalancamiento de personas y empresas y, en este ámbito, el sector financiero contribuyó a seguir avivando y ampliando el riesgo ante la carencia de medidas preventivas y con información insuficiente. El Banco de España, que seguía teniendo las competencias de regulación financiera, no informó ni actuó hasta bien avanzada la crisis. En este artículo tratamos de explicar cómo se ha producido este proceso que ha generado que la crisis financiera española haya sido de mayor intensidad que en otros países, eliminando a las cajas de ahorros y que dio lugar al rescate europeo de 2012.
\end{abstract}

Palabras clave: Banco de España, FROB, Crisis económica y financiera, euro, Regulación financiera.

\section{The Official Financial and Banking Information and the Last Economic Crisis (1999-2012). The Case of the Bank of Spain}

\begin{abstract}
The economic and financial crisis that has affected most of the developed countries in recent years has very sharp differential characteristics in each of them. In the Spanish case, the previous gestation of the crisis was driven by the introduction of the euro and the European Monetary Policy applied by the European Central Bank (ECB) that gave the false sense that we had assured in the future monetary stability with low rates of interest. This process required intermediaries to leverage individuals and companies and, in this area, the financial sector contributed to further fueling and increasing risk in the absence of preventive measures and insufficient information. The Bank of Spain, which still had the powers of financial regulation, did not act until well into the crisis.

In this paper we try to explain how this process has produced that has generated that the Spanish financial crisis has been of greater intensity than in other countries, leading to the elimination of the savings banks and the European funds rescue in 2012
\end{abstract}

Keywords: Banco de España, FROB, Economic and Financial Crisis, Euro, Financial Regulation.

Clasificación JEL: E58, E65, G21, G38

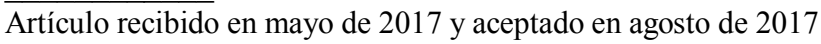

Artículo disponible en versión electrónica en la página www.revista-eea.net, ref. ə-35314 


\section{INTRODUCCIÓN}

A comienzos de este año (2017), el diario El País en una editorial ${ }^{1}$, llamaba la atención acerca de que, a pesar del tiempo transcurrido, el Banco de España aún no había dado una explicación convincente de cómo se gestó la crisis financiera en España. A pesar de la ingente cantidad de artículos y libros que se han dedicado a esta cuestión desde el año 2007, la sensación que se tiene es que muchos de los motivos que originaron la crisis en España todavía están ocultos tras multitud de explicaciones (la mayor parte de ellas interesadas y motivadas por el lugar que ocupe cada autor o "entidad interesada" en el desarrollo de la misma).

Esta no es una valoración original. El propio Banco de España ha querido salir al paso de esta inquietud y ha encargado la realización de un informe oficial que, supuestamente acabará con tantas suspicacias acerca de su papel en la generación de la crisis, prometiendo que para mayo de 2017 estaría acabado. ${ }^{2}$

Como es de presumir, ese Informe del Banco de España no será la última palabra sobre este tema ya que, como es obvio, la institución es parte del problema y serán muchos los que vean su explicación como interesada y dirigida a exculparse del desarrollo de la crisis.

En parte, ya que también hay otros motivos políticos en juego, esto es lo que está detrás de la constitución en las Cortes Españolas de una Comisión de Investigación para analizar las causas de la crisis financiera y las responsabilidades de las distintas instituciones y empresas en la misma. Tampoco en este caso es de esperar una respuesta definitiva sobre las causas de la crisis, ya que los distintos partidos políticos van a estar más interesados en las consecuencias actuales que en conocer la posible verdad objetiva (no creemos que esta sea posible de alcanzar al ser tantos los intereses en juego), pero es posible que se pueda acceder a nuevos datos e informaciones que contribuyan a despejar muchas dudas sobre las decisiones que se fueron tomando a través del tiempo y que, juntas, dieron lugar a los resultados más conocidos: desaparición de las Cajas de Ahorro, ingentes ayudas públicas, concentración bancaria, recortes económicos, etc.

Quizás por ello sea significativo destacar como las fechas del inicio de estos trabajos no son neutras. Si el Informe del Banco de España las va a fijar en el

\footnotetext{
${ }^{1}$ El País, 4-2-2017: "El Prestigio del Banco. Conviene aclarar del todo los criterios de inspección bancaria durante la crisis.".

2 El Banco de España hizo público este Informe el 15-6-2017 (Banco de España, 2017), compareciendo el Gobernador en el Congreso de los Diputados el 12-7-2017 (Linde, 2017). Este artículo está redactado antes de conocer estos documentos, por lo que no se han incorporado en el análisis que se hace en el mismo.
} 
año 2008, la Comisión Parlamentaria lo va a hacer desde el año 2000. ¿Tiene esto mucha importancia?

Aunque no dejen de tener interés, y en muchos momentos sean claves, las decisiones tomadas a partir de 2008 por las instituciones y empresas españolas no pueden explicar los motivos por los cuales se fueron acumulando los desajustes económicos y financieros que dieron lugar a su explosión a partir de 2008. El largo periodo de crecimiento económico anterior fue acumulando tensiones a todos los niveles que, en su mayor parte, fueron ignoradas o infravaloradas por todos los agentes económicos $\mathrm{y}$, especialmente, por las autoridades económicas y financieras que tenían la obligación de, al menos, señalar los riesgos en los que estábamos incurriendo.

Ciertamente, al haberse judicializado el debate con las denuncias llevadas a cabo por el FROB principalmente contra los responsables de algunas de las Cajas de Ahorro y Bancos, todas las explicaciones tienen que leerse en clave de discernir las responsabilidades penales y societarias y por lo tanto, tratar de evitar sus responsabilidades, con independencia de cualquier otra razón. La muestra hasta la fecha más evidente de este proceso lo podemos observar en Bankia, donde recientemente se ha imputado/investigado al Exgobernador del Banco de España y al Presidente de la CNMV, entre otros, por la salida a bolsa de sus acciones. ${ }^{3}$ Pero también en otros casos está en litigio el comportamiento de los reguladores y el propio Ministerio de Economía en la generación de los problemas del sistema financiero. $\mathrm{Si}$, como algunos pretenden, la responsabilidad solo es atribuible a los gestores de las empresas ¿qué sentido tiene tener órganos reguladores? Y si los responsables de los órganos reguladores actuaron con negligencia e impericia, ¿cómo se les atribuye la responsabilidad?

Como se ve, lejos estamos de poder hacer un debate sereno cuando las consecuencias son penales.

Pero lo anterior no debería paralizar todo intento de explicación de lo ocurrido.

En España existe un consenso muy generalizado acerca de los dos detonantes fundamentales de la crisis (Sudría, 2014). Estos serían la introducción de la moneda única y la formación de un nuevo mercado de capitales europeo que favoreció la aplicación de unos tipos de interés muy por debajo de los existentes hasta la fecha y, por otra parte, la crisis de las hipotecas sub prime que actuaron como detonante para el cierre de los mercados de capital a escala mundial. Cada uno de estos condicionantes tuvo un desarrollo diferenciado en función de las distintas realidades nacionales y sus exposiciones al riesgo en función de sus distintas situaciones respecto a las necesidades de financiación internacional.

\footnotetext{
${ }^{3}$ A fecha de 29-7-2017, el juez Andreu ha retirado estos cargos, pero aún están pendientes de recurso.
} 
(Arce et al., 2016; Colino et al., 2014; Estrada et al., 2016, Millaruelo et al., 2017; Ortega et al., 2012; etc.)

La situación española, al igual que la de otros países europeos que habían visto como las mayores disponibilidades de crédito barato les permitía un mayor endeudamiento en una zona monetaria supuestamente sin riesgos, fue la de utilizar al máximo esta fórmula de financiación para contribuir al crecimiento económico interno. Sin que las autoridades nacionales pusieran limitaciones a ese crecimiento, las entidades financieras, las empresas y los ciudadanos se vieron incentivados a realizar inversiones sin una previsión clara acerca de los riesgos que se estaban originando, e invirtieron en lo que daba más rendimiento y en lo que tuvieran un mayor conocimiento. El boom inmobiliario español respondió a este modelo y de una forma vista hoy en día como irresponsable se pusieron en marcha iniciativas de desarrollos urbanísticos y de construcción de viviendas muy por encima de los límites racionales para su crecimiento. (Sebastián, 2015; García Montalvo, 2014)

Este proceso también fue adoptado por otros países europeos que se habían beneficiado de los accesos a los nuevos mercados de capitales de la zona euro y de los bajos tipos de interés, por lo que el fenómeno, aunque no de tanta intensidad como en España, también acumuló riesgos importantes. (Millaruelo et al., 2017)

A esta dinámica se le sumó simultáneamente el efecto de la financiación de las hipotecas sub prime americanas. Como es sabido, el riesgo de estas operaciones inmobiliarias consistió en que, aparte de que se dieran créditos para la adquisición de viviendas a personas que difícilmente iban a cumplir sus compromisos de amortización de los préstamos, dichas operaciones se "empaquetaron" agrupadas y se distribuyeron por el sistema bancario a nivel mundial. Ante los primeros impagos de esos créditos, la desconfianza en el sistema financiero internacional corrió como la pólvora deteriorando el valor de los activos de toda la banca y cerrando los mercados de capitales mundiales ante la desconfianza sobre las entidades que estaban afectadas por esos problemas. ${ }^{4}$

La conjunción de los dos problemas anteriores produjo una "tormenta perfecta" (si se puede llamar así a algo que ha creado tantos problemas) y las instituciones internacionales y los gobiernos tardarían años en entender exactamente qué estaba ocurriendo. Los economistas tampoco tuvieron muchas respuestas para explicar el fenómeno y algunos políticos propusieron reinventar el capitalismo.

\footnotetext{
${ }^{4}$ A diferencia de lo ocurrido en España, la información suministrada por la Reserva Federal en EEUU sobre la crisis, su desarrollo y los condicionantes de la toma de decisiones ha sido impresionante. La lectura de las Memorias del Presidente de la Reserva Federal (Bernanke, 2016), no solo es un modelo de trasparencia, sino que es clave para entender la Política Económica.
} 
No es extraño pues que las autoridades españolas actuaran tan medrosamente al principio de la crisis. Al no estar afectado el sistema crediticio español por la inversión en activos procedentes de las hipotecas sub prime, el Gobierno español consideró que estábamos fuera del problema, no poniendo en marcha respuestas tempranas que, como ahora algunos defienden (Guindos, 2016) podrían haber limitado los daños. Pero no cabía mucha duda de que, si se cerraban los mercados de capitales, España se vería afectada al tener tan alta dependencia de los mismos.

A continuación vamos a ver la posición que el Gobierno español y el Banco de España adoptaron en el periodo anterior al estallido de la crisis. Respecto al Gobierno español analizaremos los testimonios de sus principales responsables y su explicación de por qué actuaron como lo hicieron, mientras que en el caso del Banco de España, hemos analizado la información que suministró al Gobierno y a los agentes económicos a través de sus Informes Anuales desde 1999 y a los Informes de Estabilidad Financiera que se iniciaron en $2002 .{ }^{5} \mathrm{La}$ fecha final que hemos considerado ha sido la de 2012 ya que en la misma se inició otra fase en relación con estos problemas.

\section{LA PERCEPCIÓN DE LA CRISIS POR EL GOBIERNO ESPAÑOL Y EL BANCO DE ESPAÑA}

Existe un consenso generalizado por parte de los analistas y las instituciones económicas acerca de la importancia de la crisis económica y financiera por la que ha atravesado España en los últimos años. No es un hecho privativo de España esta situación ya que la misma se ha inscrito dentro de un marco de crisis internacional que ha afectado a una gran cantidad de países, pero el caso español tiene sus características propias.

Son muchos los autores que en este caso asocian la crisis con el boom anterior estableciendo unos vínculos claros entre los excesos del crecimiento económico y financiero previo y las formas de la crisis asociando la relajación de los controles previos con las consecuencias posteriores. Sin embargo, las instituciones públicas y los reguladores españoles han tratado de romper ese vínculo tratando el problema como si hubiese surgido de la nada a partir de la crisis de Lehman Brothers en 2008. Este enfoque es ciertamente interesado.

A través de esta visión, se ha pretendido cargar sobre las decisiones individuales de las instituciones financieras, las empresas y los ciudadanos la responsabilidad sobre las decisiones que fueron tomando en el periodo previo a la crisis como si las mismas se hubiesen hecho fuera del marco regulador existente y con una información trasparente y adecuada de los responsables públicos. Nada más lejos de la realidad.

\footnotetext{
${ }^{5}$ En otro trabajo analizamos las aportaciones del Servicio de Estudios del Banco de España al conocimiento de este periodo. (Sevilla et al., 2015)
} 
Con independencia que toda decisión económica debe ser valorada con prudencia por los agentes implicados, no cabe ninguna duda de que estos actúan también tomando como referencia el marco informativo y las reglas que emiten las instituciones económicas y los reguladores que, además, tienen la capacidad y el deber de acotar las prácticas generales posibles en cada caso. Por citar un símil muchas veces utilizado referido a las normas de circulación, si bien es cierto que un conductor es responsable de conducir con prudencia, ¿qué ocurre cuando la señal de tráfico limita la velocidad a $90 \mathrm{~km} / \mathrm{h}$ cuando lo adecuado sería ir a $60 \mathrm{~km} / \mathrm{h}$ ?

El crecimiento económico español desde finales de los años 90 hasta bien iniciada la crisis (2010) no solo fue, como se ha observado con posterioridad, irresponsable, sino que contó con el beneplácito de las autoridades que no supieron o no quisieron "retirar el champán de la fiesta" (Sebastián, 2015).

Si lo anterior no fuera lo suficientemente grave de por sí, en el sistema financiero español se amplió, al no delimitar con precisión las diferencias entre la banca de las Cajas de Ahorro que han originado la quiebra de un modelo centenario de organización del sistema financiero y bancario español.

Con independencia de otras diferencias que mencionaremos con posterioridad, las dotaciones de capital para hacer frente a los activos de la actividad financiera funcionaban de una forma radicalmente diferente entre Cajas y Bancos. Mientras que las primeras solamente podían acceder a las ampliaciones de capital mediante las aportaciones procedentes de la distribución de los beneficios no destinados a la Obra Social de las mismas, los Bancos podían acceder al mercado de capitales mediante las ampliaciones de capital. Si bien este hecho no era desconocido para el Gobierno, como se hizo patente con la modificación de la regulación de las cuotas participativas en 2003 mediante la denominada Ley Financiera, su introducción como pasivo de las Cajas de Ahorro fue un auténtico fracaso ya que solamente una caja se atrevió a utilizar esa vía. Pero esto no produjo ninguna reacción por parte de las Administraciones españolas ya que su posición era la de que no existía un riesgo para nuestro sistema financiero.

En otro trabajo (Sevilla et al., 2015) hemos analizado el papel que tuvo en este proceso el Banco de España en relación con las investigaciones realizadas por su Servicio de Estudios. En el mismo poníamos en evidencia la poca atención que se le prestó a las diferencias existentes entre Bancos y Cajas de Ahorro en el periodo de gestación de la crisis o "falsa bonanza" como la ha titulado Miguel Sebastián (Sebastián, 2015), el que fuera Ministro de Zapatero en esa época. Ahora hemos querido hacer otra aproximación a esta problemática desde otro enfoque que, aunque no puede ser definitivo, añade otra visión sobre el periodo de gestación de la crisis. 


\subsection{El Gobierno español gestiona la "falsa bonanza": 1996-2008}

La apertura de una Comisión Parlamentaria en las Cortes Españolas en 2017 sobre el origen de la crisis financiera en España, posiblemente pueda permitir conocer algunos documentos e informes para analizar algunas de las causas que han estado en el origen de la misma. Sin embargo, la posición de los distintos implicados (órganos reguladores e instituciones especialmente) no será posiblemente tan cómoda, como lo está siendo hasta la fecha.

Al parecer, se ha establecido un consenso colectivo que atribuye a los responsables de las Cajas de Ahorro todos los males ligados a la crisis. El Ministro Guindos sintetizaba esta opinión en su comparecencia en el Senado en el pasado febrero: “...en el año 2009 y en el año 2010 estaba muy parecida al actual, es decir que no había todavía una ligazón como existió a partir del 2011 y en el 2012 entre el riesgo bancario y el riesgo macroeconómico, por qué en ese momento no se tomó la decisión de inyectar ese capital, cambiar a todos los gestores de las cajas de ahorros, reestructurar, eliminar el pésimo gobierno corporativo que teníamos y la pésima influencia política que existía en esas entidades. ¿Por qué no se hizo? Esa la gran pregunta de la comisión de investigación, si me permiten ustedes. ¿Por qué no se hizo? Nos hubiera salido mucho más barato y nos hubiéramos evitado un montón de disgustos. "[......] Pero le vuelvo a repetir que sería buenísimo ver el origen de la crisis, cuál fue la burbuja inmobiliaria, la burbuja de crédito, qué errores de política financiera cometimos, qué errores cometieron o qué aciertos tuvieron los supervisores y cuáles fueron las consecuencias del programa de asistencia financiera". (Senado, 2017, pg 29 y 30) ${ }^{6}$ (los subrayados son nuestros)

Quizás, alguno de los Senadores presentes podría haberle recordado a Luis de Guindos, que entre 2010 y 2011 fue Consejero del BMN y que dimitió para ser Ministro a finales de 2011 lo que él mismo escribió en 2009: “.9. La naturaleza de las Cajas de Ahorro sigue siendo adecuada para el futuro. No hay ninguna razón que obligue a modificar su naturaleza jurídica. Son entidades privadas de carácter fundacional cuyos derechos de propiedad están repartidos entre el conjunto de la sociedad. En un mercado abierto pueden competir en igualdad de condiciones entidades con distintas estructuras de propiedad. Lo que es necesario es establecer mecanismos para evitar la interferencia política y que garanticen la independencia y profesionalidad de la gestión." (Guindos et al., 2009, pg. 215). En el año siguiente cambiaría todo. (El subrayado en los textos anteriores es nuestro)

La tesis que mantenemos en este artículo es la de que, tanto el Gobierno español como el Banco de España no tuvieron en cuenta desde 1999 hasta 2009 el principal hecho diferencial de las Cajas de Ahorro con respecto a los bancos y

\footnotetext{
${ }^{6}$ La comparecencia fue a petición propia y de varios Senadores.
} 
que, por lo tanto, estuvieron dando informaciones y tomando decisiones erróneas que incrementaron el riesgo de la crisis al confundir a los responsables de las mismas y a la sociedad sobre el alcance de estas decisiones.

Durante los Gobiernos del Presidente Aznar, las regulaciones generales que después se han comprobado como más perniciosas, se hicieron en su mayor parte sin diferenciar los bancos de las Cajas de Ahorro: las provisiones introducidas por el Banco de España de 1999 se establecían en función de los activos de cada entidad; la financiación hipotecaria, el impulso a la liberalización del mercado del suelo o la desgravación a la inversión en la vivienda ( la gran especialidad de las Cajas en los periodos anteriores) no se vinculaba con la procedencia de los recursos. En definitiva, se consideraba que los riesgos eran comunes aunque se supiera que las respuestas del capital entre unos y otras eran muy diferentes (Sevilla et al., 2014; Abad et al., 2014).

No es cierto sin embargo que no se tomara ninguna medida, aunque las mismas, visto lo visto, no iban por el camino adecuado. Así en 2002 y 2003 se aprobaron dos Leyes que, entre otras cosas modificaron la LORCA de 1985: La Ley 44/2002 y la Ley 26/2003 mediante las cuales se incorporaban recomendaciones del Código Olivencia y Aldama que tendían a equipararlas con otras sociedades mercantiles, creando las Comisiones de Retribuciones y de Inversiones o los Informes de Gobierno Corporativo vigentes desde esas fechas, modificando también los órganos de representación o la duración de los mandatos de los Consejeros.

Fruto también de la legislación de 2002 fue la modificación por Real Decreto de 2004 (pocos días antes del cambio de Gobierno en 2004) sobre cuotas participativas de las cajas de ahorro ${ }^{7}$.

Llama la atención que estos cambios fueran tramitados de una forma "vergonzante" al ser introducidos a última hora en el trámite de esas leyes, sin un debate parlamentario más amplio, hecho éste que incluso dio lugar a que no se mencionara nada sobre estos cambios en las Exposiciones de Motivos de las dos leyes. El Gobierno de Aznar no explicaba ni hacía pedagogía sobre lo que pretendía alcanzar con esos cambios, por lo que los mismos fueron en su mayor parte interpretados como meros trámites administrativos y formales, sin ninguna carga adicional sobre la necesidad de reformas en profundidad del modelo de Cajas de Ahorro.

El Gobernador del Banco de España en esa época, Jaime Caruana, que además continuó con el nuevo Gobierno, fue consciente de los problemas que se estaban

\footnotetext{
${ }^{7}$ En buena medida este Real Decreto podría ser denominado "Decreto Guindos" ya que en esos momentos fue su principal impulsor. Fruto de sus conocimientos de la mecánica de funcionamiento de las cuotas Guindos como miembro de Lehman Brothers en España fue contratado por la CAM, junto con AFI, como asesor de la única emisión de cuotas que se hizo en España por parte de una Caja de Ahorro.
} 
originando y lo manifestó en alguna comparecencia, pero ninguna resolución vinculante se tomó para prever los efectos. ${ }^{8}$

El cambio de Gobierno en 2004 continuó con el espejismo de que no era urgente tomar medidas. (Rodriguez Zapatero, 2013; Solbes, 2013) Incluso los análisis y advertencias que algunos responsables del Gobierno habían hecho con antelación sobre los riesgos del sistema (en especial Miguel Sebastián y M.A. Fernández Ordóñez), se olvidaron tras los cambios. El nuevo Gobierno se encontró con un fuerte crecimiento económico al que no estaba dispuesto a renunciar y las denuncias que posiblemente llegaron a sus mesas, como las de los Inspectores del Banco de España en 2006 (que se conocieron públicamente mucho después), quedaron aparcadas ante la complacencia por la supuesta bonanza.

El nuevo Presidente del Gobierno, que llegó al poder tras las elecciones del 14 de marzo de 2004 tras los atentados de tres días antes, en sus Memorias (Rodríguez Zapatero, 2013), todavía mantenía su perplejidad sobre lo que había sucedido respecto a la crisis financiera, aunque para él esta se concentraba solamente en "600 días de vértigo", que es el subtítulo de su libro: "En relación con ello, hay un interrogante que permanece presente en mi cabeza: ¿por qué los mercados y las agencias de calificación en 2009, con la misma deuda neta privada externa, con un déficit público que ya era alto y con un déficit por cuenta corriente que el que alcanzó en 2010, además de con un paro muy alto, no consideraban entonces que existía riesgo alguno sobre nuestra deuda soberana? Creo que la respuesta a esta pregunta es decisiva para poder aproximarse a entender los efectos de la crisis financiera en nuestro país, la prolongación de ésta y las consecuencias sociales, económicas y politicas tan severas que ha provocado. Quizás el lector pueda imaginarse las veces que he intentado responder a esta pregunta y los esfuerzos que realicé para refutar el riesgo que podía suponer ese desequilibrio de nuestros fundamentales económicos. Baste decir en este momento que, para mí, la evolución económica de un país no cabe en un modelo matemático. Los factores que determinan en muchas ocasiones los hechos están llenos de prejuicios, de informaciones limitadas, de climas de opinión, del afán de algunos para que se cumplan sus profecías". (pg. 160-161) (El subrayado es nuestro)

No quedan muy claras las enigmáticas palabras de Zapatero, aunque previamente ya había advertido acerca de la forma que él adquiría la información sobre el sistema financiero español: "Por mi parte, debo añadir que la

\footnotetext{
${ }^{8}$ Como algún Director de Cajas dijo en aquellos momentos, "El Gobernador dice lo que debe decir, nosotros hacemos lo que tenemos que hacer".La comparecencia de Caruana en el Congreso de los Diputados el 24-7-2017 trató de explicar esta situación.
} 
información que el Banco de España me facilitaba, a través de su Gobernador, me parecía fundada, seria y realista (nadie dijo nunca lo contrario) "'. (pg.158)

Lo que queda claro de este periodo es que el nuevo Gobierno no tomó ninguna iniciativa respecto a la organización y riesgos del sistema financiero, y por lo tanto, para las Cajas de Ahorro, hasta octubre de 2008 (Real Decreto-ley 6/2008, de 10 de octubre, por el que se crea el Fondo para la Adquisición de Activos Financieros y Real Decreto-ley 7/2008, de 13 de octubre, de Medidas Urgentes en Materia Económico-Financiera en relación con el Plan de Acción Concertada de los Países de la Zona Euro.). Como recoge el Ministro Solbes en sus Memorias (Solbes, 2013, pg. 352): "Seguíamos pensando que todos estos factores iban a llevar a nuestro mercado inmobiliario a cifras más realistas, sin que se produjera un ajuste tan traumático."

Otra fuente de cara a analizar el alcance de este problema lo podemos ver en los denominados "Informe Económico del Presidente del Gobierno" publicados solamente para los años de 2007, 2008, 2009 y $2010^{10}$.

El Informe de 2007 no hacía ninguna referencia a los problemas del sistema financiero ni a las Cajas de Ahorro, mientras que en el de 2008, incluso se permitía los siguientes comentarios auto complacientes: "En cuanto al sistema financiero español, todos los indicadores lo caracterizan como solvente, eficiente y rentable, situándolo en una mejor posición que el sistema financiero norteamericano (pg. 21) En cualquier caso, en España todas las entidades financieras prestamistas son supervisadas por el Banco de España, mientras que en EE.UU. solo una pequeña parte de las hipotecas de alto riesgo están sometidas a supervisión federal."(pg. 22)

Ninguna referencia a la falta de profesionalización en las direcciones de las Cajas de Ahorro, a su politización o al riesgo ya acumulado debido al boom inmobiliario y a la financiación exterior que, con posterioridad, han sido utilizados como los causantes de nuestra crisis financiera.

Pedro Solbes, en sus Memorias (Solbes, 2013), trata de explicar su actuación en estos años y las razones de la inacción del Gobierno. En relación con la denominada "Carta de los Inspectores del Banco de España de 2006", el Ministro no recuerda que llegara hasta su mesa, por lo que la desconoció (atribuye a otros esa responsabilidad), pero menciona una respuesta del Gobierno en mayo de 2011(él ya llevaba dos años fuera del Gobierno) a una pregunta de un Diputado del PP: "La pregunta planteaba una serie de cuestiones que pueden resumirse en: ¿por qué el Gobierno no tomó medidas?, ¿por qué no se obligó a las entidades de

\footnotetext{
${ }^{9}$ Zapatero no cita a nadie que hiciera esa aseveración. De todas formas, en toda la referencia de sus Memorias a la crisis financiera, no menciona en ningún caso al Ministro Solbes.

${ }^{10}$ Estos Informes dejaron de hacerse con el Gobierno de Rajoy y el de 2011 no se hizo al coincidir con las elecciones del 20 de noviembre.
} 
crédito a dotar las provisiones suficientes para hacer frente a las pérdidas esperadas?, ¿qué medidas adoptó el Gobierno junto con el Banco de España para evitar la concesión de hipotecas superiores al ciento por ciento del valor de tasación?, ¿por qué se permitió a las entidades que siguieran aumentando su crédito promotor a partir de 2006 con el desplome de la construcción?, ¿por qué no se obligó a las entidades financieras a declarar realmente los riesgos que estaban asumiendo?..." (pg. 340)

Solbes considera que la respuesta del Gobierno fue acertada y especialmente, la siguiente argumentación: "La interacción de estos dos elementos, endurecimiento del acceso a la financiación y el deterioro de activos, ha producido una presión muy fuerte sobre nuestra economía en su conjunto y sobre el sector financiero en particular. Ni la función supervisora del Banco de España ni la regulación prudencial implantada lograron eludir el actual contexto de dificultad del sector" (pg. 342) Solbes añade que la principal preocupación tanto del Ministerio como del Banco de España fue la de "tener el mejor conocimiento de la realidad para en su caso actuar", argumentando que "Al final de la legislatura más de treinta normas habian sido aprobadas con el apoyo al menos de los dos principales partidos de la Cámara" (pg.342)

$\mathrm{Al}$ parecer, ni la información de la que se disponía era la mejor, ni las normas aprobadas tenían mucho que ver con los problemas que se acumularon y que desembocaron después en la crisis financiera y en la desaparición de las Cajas de Ahorro. ${ }^{11}$

\subsection{La información suministrada por el Banco de España durante la "falsa bonanza": Los Informes Anuales (1999-2012) y los Informes de Estabilidad Financiera (2002-2012)}

Pretendemos hacer una primera aproximación a una cuestión que, por la rapidez de los acontecimientos se le está prestando poca atención: ¿Hasta qué punto los Bancos Centrales de los países que se integraron en la zona euro fueron conscientes de las insuficiencias que el proyecto de Unión Monetaria tenía y que se pusieron de manifiesto en su desarrollo?

Sería pretencioso suponer que esta cuestión puede realizarse de una forma definitiva y clara a través de un solo estudio. Pero esto no obsta para que se puedan hacer aportaciones limitadas sobre lo que ocurrió durante el periodo de tiempo que arranca con la puesta en marcha del proyecto del euro hasta la actualidad.

Para este ejercicio de análisis, en vez de recurrir a la bibliografía que se ha elaborado sobre esta cuestión (y que llamamos la atención de que no es muy

${ }^{11}$ Un testigo directo de todo el proceso (Sebastián, 2015), explica de una forma mucho más descarnada todo este proceso. 
extensa posiblemente porque se ha considerado que es poco útil ${ }^{12}$ ), vamos a recurrir, en el caso español, a una vía indirecta sobre las preocupaciones del Banco de España sobre la misma, para ver cómo se fueron manifestando anualmente.

Lo que se pretende con el análisis es conocer, en base a las menciones que se hacen en los Informes Anuales y a los Informes de Estabilidad Financiera del Banco de España, cuáles eran las preocupaciones que tenía esta institución sobre los problemas relevantes en este periodo y, por lo tanto, hasta qué punto trasmitió a las autoridades económicas y a la sociedad, la realidad a la que estábamos asistiendo.

El Banco de España no es una entidad cualquiera y la responsabilidad sobre sus opiniones y análisis no son equivalentes a las de otros analistas privados cuyos análisis pueden estar influenciados por la entidad que les da soporte.

Hemos de tener en cuenta que, según la Ley de Autonomía del Banco de España de 1994 (hay varias modificaciones posteriores que no alteran este comentario), al Banco de España le corresponden, entre otras funciones, la de dar información financiera y estadística adecuada sobre la situación económica y financiera de España (art. 7).

En definitiva, el Banco de España es la institución encargada de llevar a cabo aquellos "estudios e informes que resulten procedentes" y no puede caber duda de que tendrán una correspondencia con todos los aspectos de materia económica y financiera de interés para el Estado español, incluidos en los mismos, no solo el Gobierno sino también las empresas y los ciudadanos españoles.

La actividad en esta materia por parte del Banco de España es muy amplia. Basta mirar en su página web el apartado de publicaciones para hacerse una idea de esta labor especializada e ingente. (Ver http://www.bde.es/bde/es/secciones/ informes/). A partir de esta base informativa, se podrían analizar los diferentes estudios que se acometieron por parte del mismo para analizar los riesgos que la formación del área euro iba a tener o estaba teniendo en la economía española y que, por los resultados observados, ha sido muy grande. Sin embargo, no nos proponemos hacer un trabajo que podría resultar tan farragoso como complejo a la hora de deducir el comportamiento del Banco de España ${ }^{13}$.

Como una medida de aproximación a esta problemática, hemos seleccionado solamente dos fuentes a la hora de analizar cuáles eran las preocupaciones que

\footnotetext{
${ }^{12}$ El actual Gobernador del Banco de España, Linde, ante los ataques del anterior Presidente de la Comisión Durao Barroso contra el Banco de España, en agosto de 2014, llegó a decir que "simplificar la crisis en el Banco de España es poco útil". El Mundo, 17-6-2014.

${ }^{13}$ En otro trabajo (Sevilla et al., 2015) hemos tratado el papel del Servicio de Estudios del Banco de España.
} 
el Banco tenía en los distintos años observados: el Informe Anual desde 1999 hasta 2012, que sintetiza adecuadamente su visión anual de los problemas más relevantes en materia económica y financiera y el Informe de Estabilidad Financiera desde su inicio en 2002 hasta 2012, que se publica cada semestre, aunque en 2002 sólo se hizo una vez. Consideramos que ambos Informes pueden ser considerados como unas fuentes muy representativas de la posición del Banco de España.

La metodología ha consistido en seleccionar una serie de palabras clave y ver la evolución que la mención a las mismas ha representado durante el periodo analizado. Aunque pueda parecer muy superficial el método, no cabe duda de que da indicios acerca de la importancia que las cuestiones relacionadas con esas palabras han experimentado a través del tiempo ${ }^{14}$.

Este trabajo se vincularía con las técnicas relacionadas con la denominada "minería de textos" o "minería textual" con las que se trata de obtener mediante sistemas de búsqueda la relación e importancia de las palabras contenidas en distintos textos, discursos o informes como medio de conocer la importancia atribuida en los mismos a estos contenidos (Ver Anexo).

\section{Los textos analizados}

Para llevar a cabo este análisis, hemos seleccionado, en el caso de los Informes Anuales del Banco de España desde 1999 (inicio de nuestra entrada en el euro), solamente la parte dedicada al Informe escrito, no teniendo en cuenta la de la Memoria del propio Banco de España, así como las referencias normativas y la publicidad de sus publicaciones.

En el caso de los Informes de Estabilidad Financiera, el análisis de los textos se remonta a 2002, que es cuando se inicia esta publicación. En este caso nos encontramos con dos publicaciones anuales, por lo que el número de datos se amplia, aunque el periodo es más corto que el referido al Informe Anual. También en este caso se ha analizado solamente la parte expositiva de los Informes de Estabilidad Financiera.

\section{Las palabras seleccionadas}

La selección de las palabras clave para su análisis se ha hecho tras una muestra de aquellas palabras que considerábamos necesariamente representativas del objetivo del trabajo (p.e. cajas de ahorro o construcción), ampliado por otras que

${ }^{14}$ Este análisis no es ajeno a otros que se realizan sobre temas de actualidad. En el último debate del Estado de la Nación, se destacaba en el discurso de Rajoy sus menciones a palabras como "corrupción" o "Cataluña" para ponderar su atención (o falta de atención) a estos temas. http://politica.elpais.com/politica/2015/02/24/actualidad/1424774364_328675.html. [Último acceso: 29-7-2017]. 
podían tener relación con el objeto principal (p.e. Provisiones), con independencia de su utilización o no. Para no complejizar el análisis nos centramos en 16 palabras en ambos casos. Ciertamente, el análisis de las palabras lleva aparejado también el diferente sentido que se le puede dar a las mismas y, en el caso contrario, cómo se puede mencionar el mismo concepto con palabras distintas (por ejemplo, para citar a "bancos" y "cajas de ahorro", puedes utilizar "entidades de crédito"), pero estos son problemas que hay que aceptar en este tipo de análisis, de ahí la necesidad de utilizar palabras o citas combinadas.

\section{Tabla 1}

Número de veces que el Banco de España utiliza las palabras clave en su Informe Anual. Informe Anual. Banco de España 1999-2012

\begin{tabular}{|c|c|c|c|c|c|c|c|c|c|c|c|c|c|c|}
\hline Palabras clave/Años & $\mathbf{1 9 9 9}$ & $\mathbf{2 0 0 0}$ & $\mathbf{2 0 0 1}$ & $\mathbf{2 0 0 2}$ & $\mathbf{2 0 0 3}$ & $\mathbf{2 0 0 4}$ & $\mathbf{2 0 0 5}$ & $\mathbf{2 0 0 6}$ & $\mathbf{2 0 0 7}$ & $\mathbf{2 0 0 8}$ & $\mathbf{2 0 0 9}$ & $\mathbf{2 0 1 0}$ & $\mathbf{2 0 1 1}$ & $\mathbf{2 0 1 2}$ \\
\hline Bancos & 20 & 26 & 18 & 13 & 10 & 17 & 0 & 2 & 11 & 31 & 10 & 17 & 22 & 54 \\
\hline Bancos Centrales & 2 & 3 & 5 & 2 & 10 & 9 & 17 & 11 & 15 & 41 & 36 & 4 & 9 & 11 \\
\hline $\begin{array}{c}\text { Bancos Centrales } \\
\text { Nacionales }\end{array}$ & 4 & 1 & 6 & 2 & 1 & 4 & 3 & 0 & 0 & 0 & 0 & 1 & 2 & 3 \\
\hline Cajas & 8 & 11 & 8 & 4 & 4 & 13 & 0 & 0 & 0 & 0 & 4 & 58 & 13 & 1 \\
\hline Construcción & 30 & 23 & 27 & 34 & 67 & 51 & 52 & 64 & 105 & 72 & 53 & 31 & 40 & 28 \\
\hline Crisis & 26 & 25 & 47 & 39 & 14 & 10 & 7 & 4 & 5 & 224 & 303 & 237 & 218 & 268 \\
\hline $\begin{array}{c}\text { Entidades de } \\
\text { crédito }\end{array}$ & 16 & 17 & 17 & 20 & 10 & 7 & 33 & 16 & 23 & 25 & 22 & 28 & 29 & 23 \\
\hline FGD & 0 & 0 & 0 & 0 & 0 & 0 & 0 & 0 & 0 & 0 & 0 & 1 & 5 & 3 \\
\hline FROB & 0 & 0 & 0 & 0 & 0 & 0 & 0 & 0 & 0 & 0 & 13 & 28 & 26 & 22 \\
\hline Inmobiliario & 1 & 1 & 5 & 7 & 4 & 3 & 10 & 49 & 98 & 76 & 32 & 37 & 32 & 43 \\
\hline Morosidad & 4 & 1 & 4 & 3 & 5 & 3 & 1 & 4 & 11 & 8 & 19 & 9 & 15 & 8 \\
\hline Preferentes & 1 & 0 & 0 & 0 & 3 & 1 & 15 & 0 & 0 & 3 & 3 & 1 & 7 & 0 \\
\hline Provisiones & 6 & 3 & 3 & 5 & 8 & 2 & 1 & 3 & 4 & 3 & 8 & 8 & 14 & 8 \\
\hline Sector inmobiliario & 0 & 0 & 4 & 1 & 1 & 1 & 4 & 12 & 23 & 20 & 20 & 10 & 9 & 10 \\
\hline solvencia & 1 & 0 & 1 & 3 & 3 & 8 & 5 & 6 & 9 & 26 & 11 & 7 & 11 & 5 \\
\hline Suelo & 1 & 4 & 8 & 2 & 1 & 3 & 5 & 6 & 5 & 1 & 1 & 0 & 3 & 4 \\
\hline
\end{tabular}

Fuente: Elaboración propia con datos de los Informes Anuales del Banco de España 1999-2012.

Tabla 2

Número de veces que el Banco de España utiliza las palabras clave en sus Informes Semestrales de Estabilidad Financiera Informe Semestral de Estabilidad Financiera del Banco de España 2002-2012

\begin{tabular}{|c|c|c|c|c|c|c|c|c|c|c|c|}
\hline Palabras clave/ Años & $\mathbf{2 0 0 2}$ & $\mathbf{2 0 0 3}$ & $\mathbf{2 0 0 4}$ & $\mathbf{2 0 0 5}$ & $\mathbf{2 0 0 6}$ & $\mathbf{2 0 0 7}$ & $\mathbf{2 0 0 8}$ & $\mathbf{2 0 0 9}$ & $\mathbf{2 0 1 0}$ & $\mathbf{2 0 1 1}$ & $\mathbf{2 0 1 2}$ \\
\hline Bancos & 51 & 115 & 134 & 299 & 122 & 63 & 127 & 49 & 36 & 31 & 48 \\
\hline Bancos Centrales & 3 & 7 & 18 & 12 & 11 & 25 & 25 & 22 & 6 & 6 & 18 \\
\hline Bancos Centrales Nacionales & 0 & 0 & 0 & 1 & 2 & 2 & 0 & 3 & 1 & 1 & 2 \\
\hline Cajas & 32 & 80 & 88 & 236 & 88 & 5 & 3 & 7 & 57 & 57 & 3 \\
\hline
\end{tabular}


Tabla 2 (Continuación)

Número de veces que el Banco de España utiliza las palabras clave en sus Informes

Semestrales de Estabilidad Financiera

Informe Semestral de Estabilidad Financiera del Banco de España 2002-2012

\begin{tabular}{|c|c|c|c|c|c|c|c|c|c|c|c|}
\hline Palabras clave/ Años & $\mathbf{2 0 0 2}$ & $\mathbf{2 0 0 3}$ & $\mathbf{2 0 0 4}$ & $\mathbf{2 0 0 5}$ & $\mathbf{2 0 0 6}$ & $\mathbf{2 0 0 7}$ & $\mathbf{2 0 0 8}$ & $\mathbf{2 0 0 9}$ & $\mathbf{2 0 1 0}$ & $\mathbf{2 0 1 1}$ & $\mathbf{2 0 1 2}$ \\
\hline Construcción & 3 & 17 & 32 & 46 & 45 & 25 & 18 & 22 & 46 & 40 & 47 \\
\hline Crisis & 3 & 7 & 8 & 7 & 6 & 10 & 31 & 56 & 51 & 56 & 42 \\
\hline Entidades de crédito & 6 & 33 & 35 & 85 & 84 & 21 & 30 & 20 & 10 & 14 & 25 \\
\hline FGD & 0 & 0 & 0 & 0 & 0 & 0 & 4 & 2 & 2 & 0 & 4 \\
\hline FROB & 0 & 0 & 0 & 0 & 0 & 0 & 0 & 20 & 21 & 54 & 22 \\
\hline Inmobiliario & 2 & 3 & 13 & 17 & 25 & 17 & 16 & 9 & 22 & 10 & 16 \\
\hline Morosidad & 12 & 48 & 45 & 87 & 64 & 90 & 84 & 110 & 62 & 16 & 41 \\
\hline Preferentes & 38 & 16 & 21 & 12 & 1 & 10 & 8 & 9 & 4 & 5 & 3 \\
\hline Provisiones & 3 & 12 & 5 & 25 & 35 & 13 & 23 & 88 & 52 & 46 & 35 \\
\hline Sector inmobiliario & 0 & 1 & 10 & 13 & 9 & 7 & 9 & 5 & 10 & 9 & 8 \\
\hline Solvencia & 30 & 60 & 67 & 96 & 109 & 67 & 75 & 80 & 70 & 40 & 39 \\
\hline Suelo & 0 & 0 & 0 & 0 & 0 & 0 & 0 & 1 & 1 & 1 & 20 \\
\hline
\end{tabular}

Nota: Están acumulados anualmente los dos semestres. 2002 es un solo semestre.

Fuente: Elaboración propia con datos de los Informes Semestrales de Estabilidad Financiera del Banco de España 2002-2012.

\section{Los resultados individuales}

Podemos ver gráficamente algunos resultados individuales para ver la coherencia de las preocupaciones del Banco de España en los distintos periodos de tiempo. En este caso, mencionamos las referencias a la palabra "Cajas de Ahorro".

Figura 1

Mención de la palabra "Cajas" por el Banco de España citadas en el Informe Anual 1999-2012

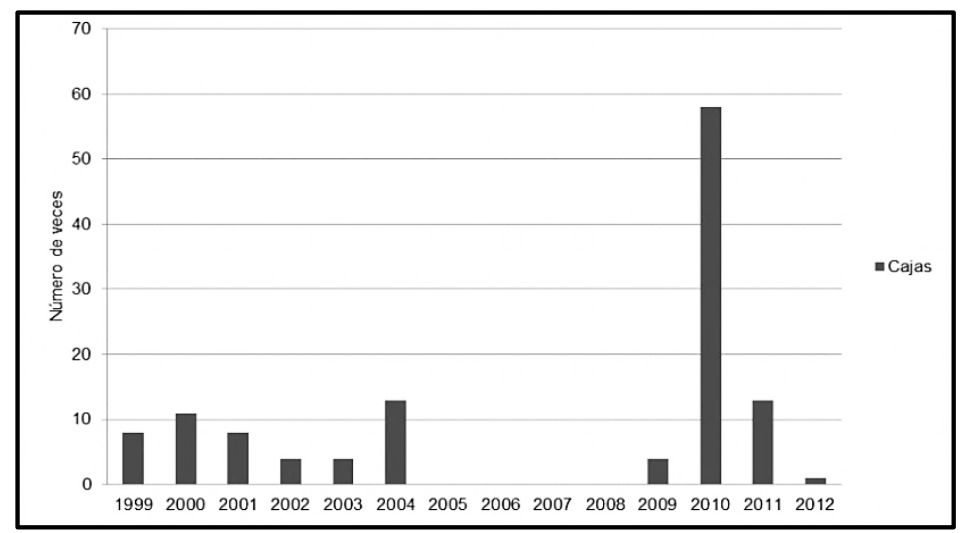

Fuente: Elaboración propia con datos de los Informes Anuales del Banco de España 1999-2012. 
Con los datos referidos a las "Cajas de Ahorro", podemos ver en las Figuras anteriores las menciones que se hacen durante el periodo, de lo que podemos deducir el interés que sobre las mismas tenía el Banco de España. Si tenemos en cuenta los problemas que se pusieron en evidencia a partir de 2010, llama poderosamente la atención la ausencia de menciones a las mismas en los Informes Anuales entre 2005 y 2008 y la poca o nula atención en el IEF entre 2007 y 2009 , los años del inicio de la crisis. ¿A qué era debido? ¿Despreciaba el Banco de España los riesgos que las mismas tenían o consideraba que este riesgo era común al de los bancos o, por extensión, a todo el sistema financiero?

Figura 2

Mención de las palabras "Cajas" por el Banco de España. Informe de Estabilidad Financiera 2002-2012

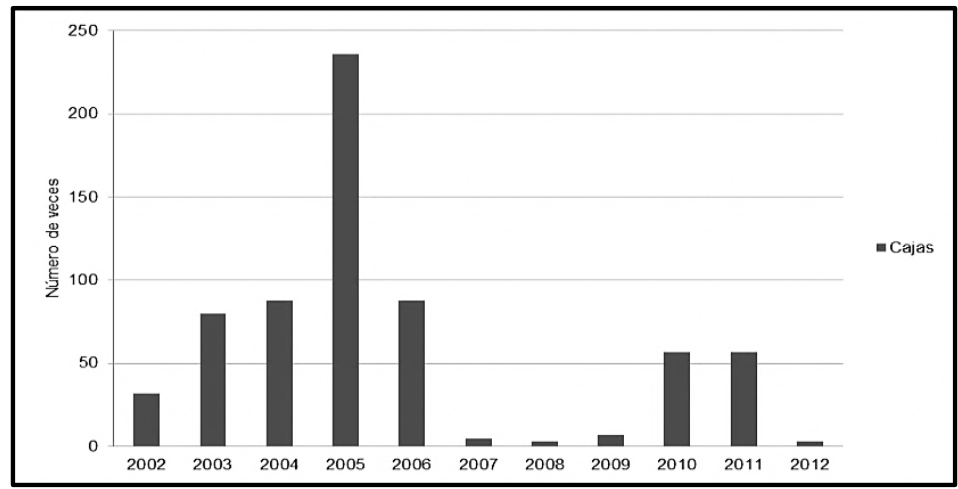

Fuente: Elaboración propia con datos de los Informes Semestrales de Estabilidad Financiera del Banco de España 2002-2012.

Figura 3

Mención de las palabras "Bancos", "Cajas" y "Entidades de crédito" por el Banco de España. Informe Anual 1999-2012

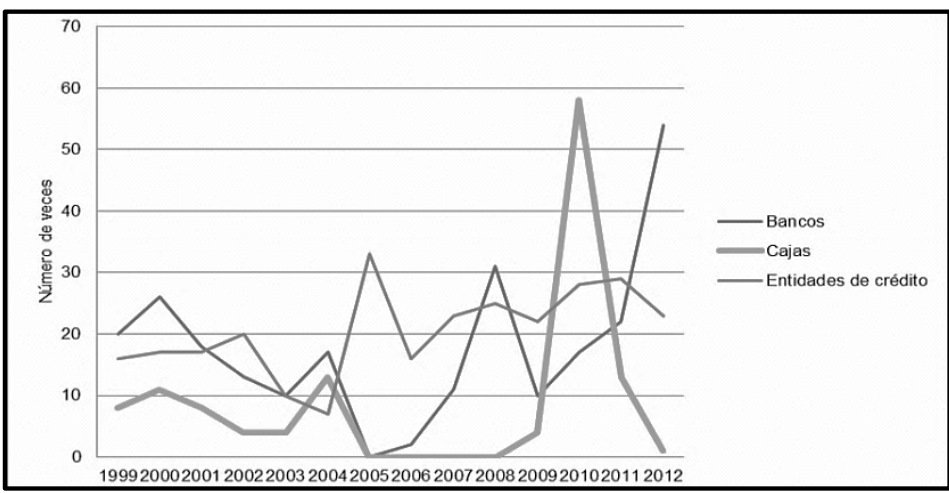

Fuente: Elaboración propia con datos de los Informes Anuales del Banco de España 1999-2012. 
Figura 4

Mención de las palabras "Bancos", "Cajas" y "Entidades de crédito" por el Banco de España. Informe de Estabilidad Financiera 2002-2012

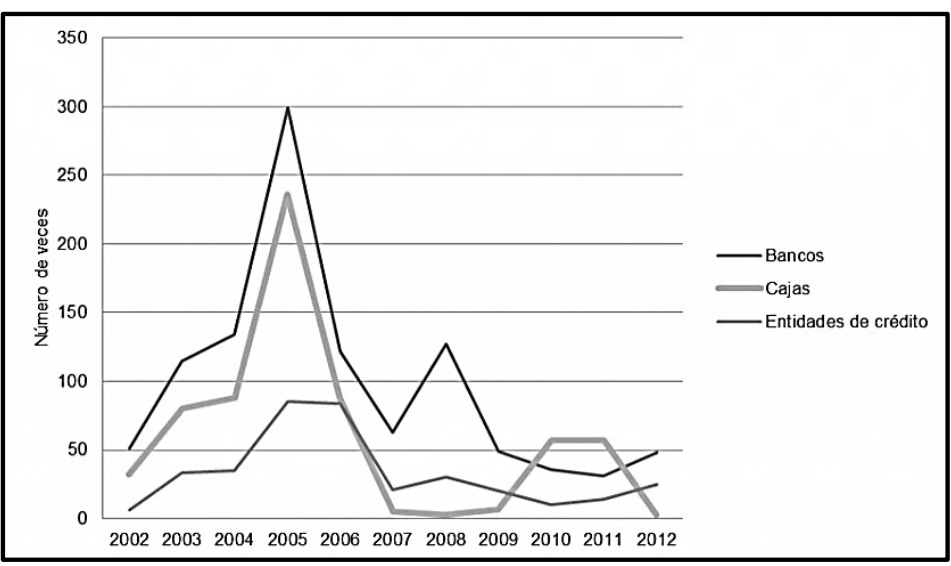

Fuente: Elaboración propia con datos de los Informes Semestrales de Estabilidad Financiera del Banco de España 2002-2012.

Figura 5

Mención de las palabras "Cajas" y "Crisis" por el Banco de España. Informe Anual 1999-2012

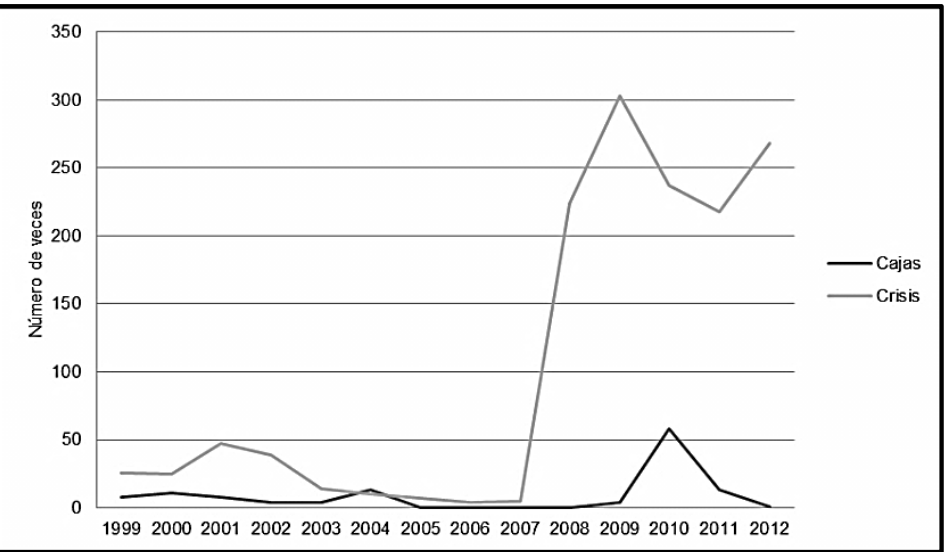

Fuente: Elaboración propia con datos de los Informes Anuales del Banco de España 1999-2012. 
Figura 6

Mención de las palabras "Cajas" y "Crisis" por el Banco de España. Informe de Estabilidad Financiera 2002-2012

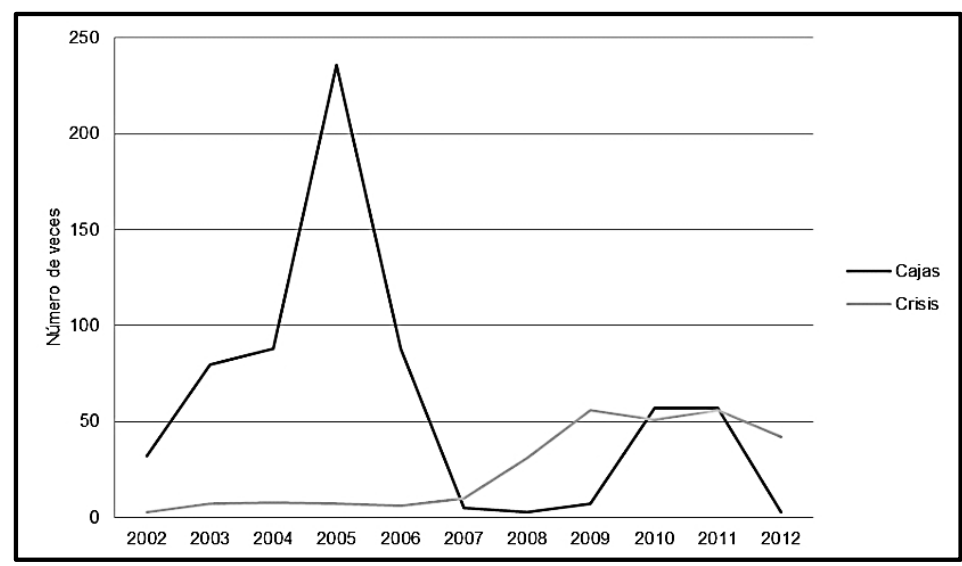

Fuente: Elaboración propia con datos de los Informes Semestrales de Estabilidad Financiera del Banco de España 2002-2012.

Figura 7

Mención de las palabras "Cajas" y otras por el Banco de España. Informe Anual 1999-2012

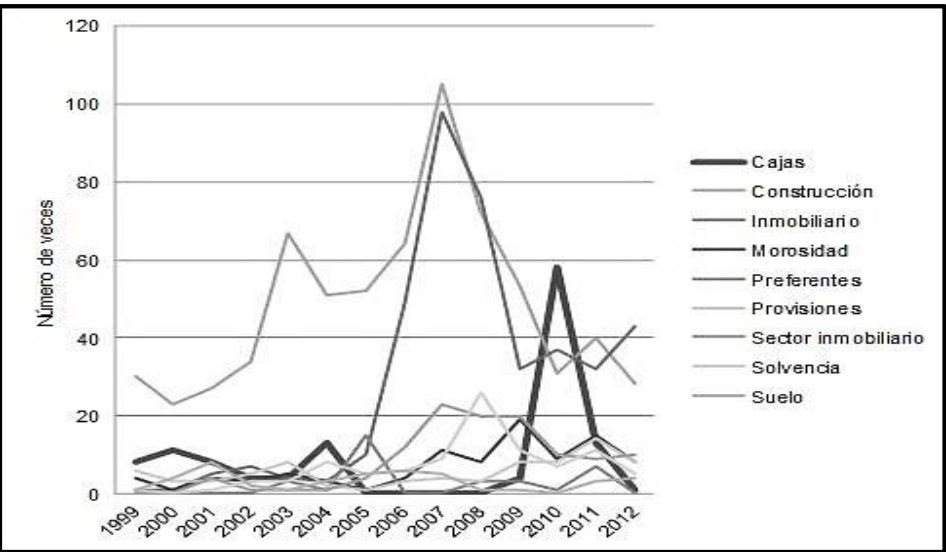

Fuente: Elaboración propia con datos de los Informes Anuales del Banco de España 1999-2012. 
Figura 8

Mención de las palabras "Cajas" y otras por el Banco de España. Informe de Estabilidad Financiera 2002-2014

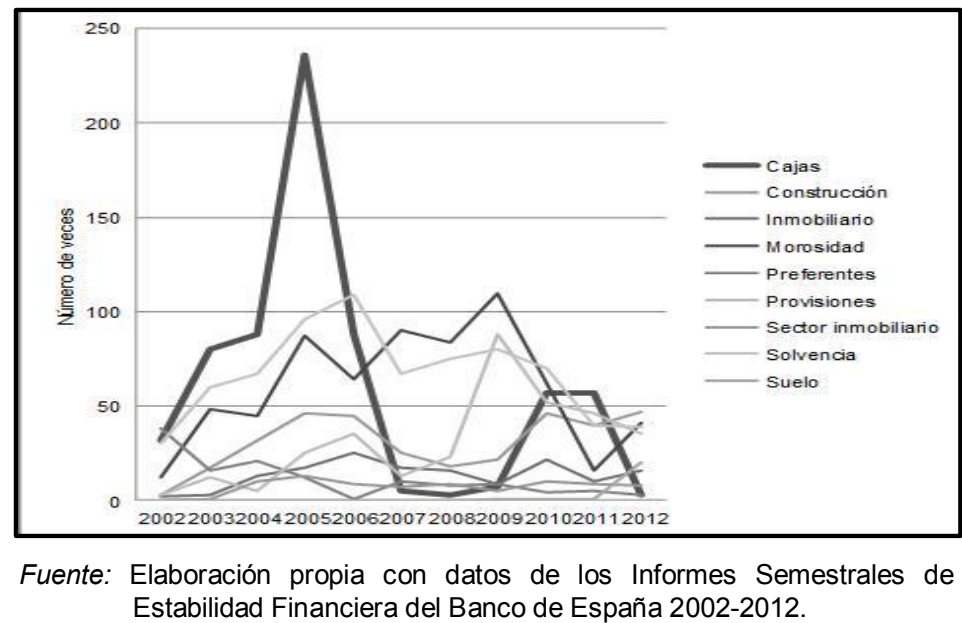

\section{La interpretación de los resultados}

De los datos y gráficos anteriores se pueden deducir algunas evidencias. Las menciones a la palabra "Cajas de Ahorro", si bien fue utilizada hasta el año 2005 con bastante frecuencia por el Informe de Estabilidad financiera (en adelante IEF), en ningún caso tenía relación con otras variables, especialmente asociado a la palabra "Crisis". Esto es si cabe más evidente en los Informes anuales del Banco de España (en adelante IA). Especialmente el periodo que va de 2005 a 2009, disminuye notablemente la mención a las mismas y llega a desaparecer en el caso del IA durante los años 2005 a 2008 y no es hasta 2010 cuando vuelve a aparecer, incrementándose notablemente en 2010 en ambos Informes. Hasta 2010 son mucho más numerosas las referencias a las "Entidades Financieras" e incluso a los "Bancos", por lo que da la impresión derivada de este análisis que las "Cajas de Ahorro" no fueron motivo de preocupación durante este periodo $y$, difícilmente se podría haber percibido a través de estos Informes, que se estaban acumulando fuertes riesgos que afectaban preferentemente a estas entidades debido, especialmente a la solvencia de las mismas que fue, en definitiva el talón de Aquiles de la crisis financiera en España. Sin entrar en los motivos respecto a esta falta de preocupación por el análisis diferenciado de estas entidades, lo que se pone en evidencia es que el Banco de España no lo tuvo en cuenta en el periodo de gestación de la crisis.

En un análisis sobre la presencia de la palabra "burbuja" en los medios de comunicación, M. Illueca (Illueca, 2014) ha llegado a preguntarse "¿por qué nadie nos avisó?". Ya hemos comentado con anterioridad que la responsabilidad 
tanto de los medios como la de los Informes de las entidades privadas, viene referenciada a la credibilidad de cada uno de ellos. Pero esto es distinto a la responsabilidad del Banco de España como autoridad crediticia y reguladora ya que sus funciones tienen un alcance público clave en la economía española. Y si esto es así, ¿por qué, al menos, no nos avisó?

\section{CONCLUSIONES}

Como hemos expuesto inicialmente, la tesis que mantenemos en este artículo es la de que, tanto el Gobierno español como el Banco de España no tuvieron en cuenta el principal hecho diferencial de las Cajas de Ahorro con respecto a los bancos y que, por lo tanto, estuvieron dando informaciones y tomando decisiones erróneas que incrementaron el riesgo de la crisis al confundir a los responsables de las mismas y a la sociedad sobre el alcance de sus decisiones. Para comprobar esta hipótesis hemos utilizado dos procedimientos distintos. Por un lado, hemos realizado un análisis cuantitativo de las referencias de varias palabras individuales y cruzadas contenidas en los Informes Anuales del Banco de España entre 2000 y 2012 y del Informe de Estabilidad Financiera del Banco de España entre el segundo semestre de 2002 y 2012. Por otro lado hemos analizado las manifestaciones públicas de los distintos responsables del Gobierno, especialmente aquellas donde se trata de explicar las razones y su conocimiento del alcance de la crisis financiera y los motivos por los cuales tomaron las decisiones que tomaron. De la conjunción de ambos análisis, se pone en evidencia que ni el Banco de España fue capaz de hacer un análisis previo de los riesgos que estaba asumiendo el sistema financiero español y, por lo tanto, no trasmitió a los responsables gubernamentales dichos riesgos, ni el propio Gobierno tuvo conciencia de ese riesgo por ninguna otra vía.

El mayor error estuvo asociado a las Cajas de Ahorro. Aunque no era un secreto los problemas asociados a estas instituciones y su carácter diferencial respecto a los bancos, especialmente en lo referente a sus necesidades de capital ante un escenario adverso, ni los análisis ni las decisiones que se tomaron estuvieron a la altura del problema hasta bien iniciada la crisis. Las referencias contenidas en los Informes analizados evidencian que se analizaba el sistema financiero español como un todo, sin prestar una atención especial y diferenciada a las Cajas de Ahorro y las cuestiones relacionadas con sus posibilidades de capitalización a través de las "cuotas participativas" no fueron incorporadas como una cuestión primordial. Cuando se plantea este problema ya era tarde para que sobrevivieran. Los Sistemas Institucionales de Protección no dejaron de ser un sistema de transición para la bancarización total del sistema financiero español (Restoy, 2016).

Es evidente que cada entidad fue responsable de sus decisiones en cuanto a la expansión de sus balances y sus riesgos, pero lo que se pone también en 
evidencia es que la información "oficial" de la que se dispuso no fue la adecuada, ni para esas entidades ni para el Gobierno y ahí, el Banco de España no cumplió su función.

\section{REFERENCIAS BIBLIOGRÁFICAS}

ABAD GONZÁLEZ, J. y GUTIÉRREZ LÓPEZ, C. (2014). "Evaluación de la solvencia bancaria. Un modelo basado en las pruebas de resistencia de la banca española". Estudios de Economía Aplicada, 32(2), pp. 593-616.

ARCE, O., HURTADO, S. y THOMAS, C. (2016). "Sinergias entre Política Monetaria y Políticas Nacionales en la Unión Monetaria". Boletín Económico. Banco de España, octubre 2016, pp. 33-41.

BANCO DE ESPAÑA. Informe Anual. Años 1999-2012.

BANCO DE ESPAÑA. Informe de Estabilidad Financiera. Informes semestrales. Desde 2002 hasta 2012.

BANCO DE ESPAÑA (2017). Informe sobre la crisis financiera y bancaria en España, 2008-2014. Madrid: Banco de España. Mayo 2017. Disponible en: https://www.bde.es/f/webbde/Secciones/Publicaciones/OtrasPublicaciones/Fich/l nformeCrisis_Completo_web.pdf [Último acceso: 29-7-2017].

BERGES, A.; DE GUINDOS, L.; LINDE, L. MARTÍNEZ-PUJALTE, V.; ONTIVEROS, E.; RODRÍGUEZ, J.; SEVILLA; J.; TORME, A.; UBIDE, A.; VALERO, F.J. (2009). Pasado, presente y futuro de las Cajas de Ahorro. Pamplona: Ed Aranzadi.

BERNANKE, B. S. (2016). El valor de actuar. Memoria de una crisis y sus secuelas. Barcelona: Ed. PenÍnsula. Huellas.

COMISIÓN NACIONAL DEL MERCADO DE VALORES (2016). Guía técnica de buenas prácticas para la aplicación del principio «cumplir o explicar». 15-7-2016. Disponible en: https://www.cnmv.es/DocPortal/Publicaciones/CodigoGov/GuiaCumplirExplicar.pdf. [Último acceso: 29-7-2017].

COLINO, J.L. y GONZÁLEZ, J.C. (eds/dirs) (2014). Las Cajas de Ahorros y la prevención y tratamiento de la crisis de las entidades de crédito. Granada. Comares.

ESTRADA, A. and SAURINA, J. (2016). "Spanish boom-bust and macroprudential Policy. BdE”. Revista de Estabilidad Financiera, n³0, Mayo 2016, pp. 35-61.

FERNÁNDEZ ORDÓÑEZ, M.A. (2015). Economistas, políticos y otros animales. Barcelona: Península.

FRANCÉS, J. (2013). ¡Que vienen los lobbies! El opaco negocio de la influencia en España. Barcelona: Destino.

GARCÍA MONTALVO, J. (2014). "Crisis financiera, reacción regulatoria y el futuro de la banca en España". Estudios de Economía Aplicada, 32(2), pp. 497-528.

ILLUECA, M. (2014). "Medios de comunicación y crisis financiera: ¿por qué nadie nos avisó?". Cuadernos de Periodistas, № 27, pp. 81-93.

JACQUET, P. and PISANI-FERRY, J. (2001). "Economic policy co-ordination in the Eurozone: what has been achieved? What should be done?" SEI Working Paper, №. 40, pp. 3-23. 
Juzgado de Instrucción n 4 de la Audiencia Nacional (2016). Los Informes de Cassaus sobre Bankia. 16-10-2016. Disponible en: http://www.ara.cat/2016/06/08/Escrito_ pidiendo_imputacion_CNMV-BdE_08-06-16_-definitivo.pdf?hash=833d6c10b260c0a 3125047e-48b668ac0170f7363. [Último acceso: 16-8-2017].

LEY 31/1985, de 2 de agosto, de regulación de las normas básicas sobre órganos rectores de las Cajas de Ahorro. (LORCA).(BOE de 9-8-1985).

LEY 13/1994, de 1 de junio, de autonomía del Banco de España. (BOE no 131, de 2 de junio de 1994).

LEY 44/2002, de 22 de noviembre, de Medidas de Reforma del Sistema Financiero. (BOE n² 281, de 23 de noviembre de 2002).

LEY 26/2003, de 17 de julio, por la que se modifican la Ley $24 / 1988$, de 28 de julio, del Mercado de Valores, y el texto refundido de la Ley de Sociedades Anónimas, aprobado por el Real Decreto Legislativo 1564/1989, de 22 de diciembre, con el fin de reforzar la transparencia de las sociedades anónimas cotizadas. BOE $n^{\circ} 171$, de 18 de julio de 2003.

LINDE, L.M. (2017). El Banco de España en la crisis. El País 10-2-2017.

LINDE, L. M. (2017). Comparecencia del gobernador del Banco de España ante la Comisión de Investigación de la crisis financiera de España y el programa de asistencia financiera en el Congreso de los Diputados. 12-7-2017. Disponible en: https://www.bde.es/f/webbde/GAP/Secciones/SalaPrensa/IntervencionesPublicas /Gobernador/Arc/Fic/linde120717.pdf [Último acceso: 29-7-2017]

MILLARUELO, A. y DEL RíO, A. (2017). "El coste de las intervenciones en el sector financiero desde 2008 en los países de la UE". Banco de España. Boletín Económico 2/2017. Artículos analíticos. 6 de abril de 2017, pp 1-13.

MISSÉ, A. (2016). La gran estafa de las preferentes. Abusos e impunidad de la banca durante la crisis financiera en España. Barcelona: Ed. Alternativas Económicas.

NIN, J. M. (2017). Por un crecimiento racional. De la gran recesión al estancamiento. Soluciones para competir en un mundo digital. Barcelona: Deusto SA Ediciones.

ONTIVEROS, E. y VALERO, F.J. (dir) (2008). España en contraste. Financiación de la economía. Madrid: AFI.

ORTEGA, E y PEÑALOSA, J. (2012). "Claves de la crisis económica española y retos para crecer en la UEM". Banco de España. Documentos Ocasionales. № 1201. 2012.

PALAFOX, J. (2017). Cuatro vientos en contra. El porvenir económico de España. Barcelona: Ediciones de Pasado y Presente, S.L.

PRESIDENCIA DEL GOBIERNO. Oficina Económica del Presidente del Gobierno (2007). Informe Económico del Presidente del Gobierno 2007. Madrid, abril de 2007.

PRESIDENCIA DEL GOBIERNO. Oficina Económica del Presidente del Gobierno (2008). Informe Económico del Presidente del Gobierno 2008. Madrid, junio de 2008

PRESIDENCIA DEL GOBIERNO. Oficina Económica del Presidente del Gobierno (2010). Informe Económico del Presidente del Gobierno 2010. Madrid, diciembre de 2010

REAL DECRETO 302/2004, de 20 de febrero, sobre cuotas participativas de las cajas de ahorros. (BOE N 54 de 3 de marzo de 2004).

REAL DECRETO-LEY 6/2008, de 10 de octubre, por el que se crea el Fondo para la Adquisición de Activos Financieros. (BOE n² 248, de 14 de octubre de 2008). 
REAL DECRETO-LEY 7/2008, de 13 de octubre, de Medidas Urgentes en Materia Económico-Financiera en relación con el Plan de Acción Concertada de los Países de la Zona Euro. BOE n 248 de 14 de octubre de 2008).

RESTOY, F. (2016). Los retos del marco de resolución europeo. Clausura de las Jornadas "Gobierno corporativo y crisis de entidades de crédito", Departamento de Derecho Mercantil, UCM (Madrid) 29.11.2016. Disponible en: https://www.bde.es/ f/webbde/GAP/Secciones/SalaPrensa/IntervencionesPublicas/Subgobernador/Arc/Fi c/restoy291116.pdf [Último acceso: 16-8-2017].

RODRÍGUEZ ZAPATERO, J.L. (2013). El Dilema. 600 días de vértigo. Barcelona: Ed Planeta.

SEBASTIÁN, M. (2015). La falsa bonanza. Cómo hemos llegado hasta aquí y cómo intentar que no se repita. Barcelona: Ediciones Península.

SENADO (2017). Comparecencia del Ministro de Economía, Industria y Competitividad, D. Luis de Guindos Jurado, ante la Comisión de Economía, Industria y Competitividad, para informar sobre las previsiones de coste para el estado de todo el proceso de reestructuración bancaria y, en particular, el correspondiente a Bankia. Diario de Sesiones 15-2-2017. Disponible en: http://www.senado.es/web/ actividadparlamentaria/sesionescomision/detallecomisiones/sesionescomision/sesionc elebrada/index.html?id=S011005\&idConv=1\&idSes=3\&legis=12\&celebrada=S. [Último acceso: 16-8-2017].

SEVILLA, M; PARDO, G.; TORREGROSA, T. (2011). "La reforma de las cajas de ahorro y la cuestión del crédito a la economía española". Anales de Economía Aplicada. ASEPELT 2011, pp. 2377-2404.

SEVILLA, M., y TORREGROSA, T. (2014). "El papel del Banco de España en el hundimiento de las Cajas de Ahorro españolas". Anales de Economía Aplicada. ASEPELT 2014, pp. 307-332.

SEVILLA, M., TORREGROSA, T. y NÚÑEZ, M. (2015). "La contribución de los Bancos Centrales de la zona euro a la crisis financiera. El papel del Banco de España y su Servicio de Estudios". Anales de Economía Aplicada. ASEPELT, 2015, pp. 665-683.

SOLBES, P. (2013). Recuerdos. 40 años de servicio público. Barcelona: Deusto Ediciones.

SUÁREZ, J. (2010). The Spanish Crisis: Background and Policy Challenges. CEPR Discussion Paper No. DP7909. Available at SSRN: https://ssrn.com/abstract= 1640986 [Último acceso: 29-7-2017].

SUDRIÀ, C. (2014). "Las crisis bancarias en España: Una perspectiva histórica”. Estudios de Economía Aplicada, 32(2), pp. 473-496.

TRIBUNAL DE CUENTAS (2017). Informe de fiscalización del proceso de reestructuración bancaria. Ejercicios 2009 a 2015. Sesión de 22 de diciembre de 2016. № 1.190. Disponible en: http://www.tcu.es/tribunal-de-cuentas/es/search/alfresco/index.html? entrance=FIS. [Último acceso: 16-8-2017].

VILARASAU, J. (2012). Memorias. El extraño camino a "la Caixa". Barcelona: RBA Ediciones. 


\section{Anexo}

\section{El proceso de búsqueda de palabras en los documentos en PDF del Banco de España}

En un primer momento, la correlación entre las preocupaciones del Banco de España reflejadas en sus Informes fue realizada de forma manual y reiterativa en todos y cada uno de los documentos analizados, lo que permitía también ver si las menciones a cada palabra iba asociada a alguna problemática concreta. Para confirmar que dichos datos no contuviesen errores, se confirmaron con la herramienta PDFWordCountTool que fue elaborada por el informático Luis Lucas al que agradecemos su colaboración. Los datos de ambos procedimientos coinciden.

PDFWordCountTool es una aplicación en línea de comando desarrollada íntegramente en Python con el apoyo de la librería PDFMiner que analiza una serie de ficheros en formato pdf determinados en proceso de ejecución para obtener el número de ocurrencias de una serie de palabras o grupos de palabras también establecidos en tiempo de ejecución y devuelve como resultado una tabla indicando las ocurrencias de cada palabra o grupo de palabras en cada fichero.

\section{¿Cómo funciona?}

La aplicación puede ser invocada por línea de comando y requiere 3 parámetros: pdfwordcount files_file.txt words_file.txt out_file.csv

Donde:

- files_file.txt es un fichero de texto que contiene una relación de ficheros a procesar seguido del intervalo de páginas, de tal manera que en cada línea habrá un fichero, tal que así: nombre_fichero página_inicio página_final. Por ejemplo:

1. inf1999.pdf 11119

2. inf2000.pdf 11129

- words_file.txt es un fichero de texto que contiene una relación de palabras o grupos de palabras (una por línea) a buscar en cada uno de los ficheros. Por ejemplo:

1. Auditoría

2. Bancos

3. Bancos Centrales

- out_file.csv es el nombre del fichero donde se almacenará la salida en formato CSV (comma-separated values), compatible con las hojas de cálculos actuales. 
Durante la ejecución de la aplicación se mostrará por consola el estado de progreso y los errores que puedan encontrarse.

\section{El lenguaje de programación}

Hemos elegido Python por ser un lenguaje de programación de alto nivel conveniente para un desarrollo rápido de código. Su filosofía de diseño enfatiza la simplicidad y legibilidad de código. Además es un lenguaje multiparadigma, en el que varios estilos de programación son compatibles, y es un lenguaje interpretado en lugar de compilado, multiplataforma, gratuito y open source, gozando de una gran comunidad de usuarios.

\section{La librería PDFMiner}

Para acceder y decodificar el contenido de los ficheros PDF hemos optado por utilizar la librería de Yusuke Shinyama, PDFMiner, con licencia MIT. De todas las librerías que hemos probado para extraer el texto de ficheros PDF, PDFMiner es la más rápida en ejecución, la que más casuística pdf abarca y la más actualizada, por lo que la decisión no ha sido difícil.

\section{Detalle del código}

El código de la aplicación se encuentra en un único fichero .py distribuido en la función main y tres funciones auxiliares. En la función main (línea 40), tras comprobar los argumentos, recorremos los ficheros que contienen los nombres de ficheros pdf y las palabras a buscar mediante dos bucles anidados. Antes de empezar el bucle interno que recorre las palabras a buscar, extraemos de cada fichero pdf el texto incluido en las páginas detalladas en el fichero de entrada con la función convert (línea 11), que es donde hacemos las llamadas pertinentes a la API de librería PDFMine. Posteriormente, por cada texto de cada fichero, recorremos todas las palabras o grupos de palabras para llamar a la función getWordCount (línea 36) con cada palabra y cada texto extraído del pdf como argumentos.

La función getWordCount toma como argumentos dos strings (texto donde buscar y palabra a buscar), y devuelve el tamaño del resultado de la función findWohleWord que a su vez, invoca a la función findall de una expresión regular construida añadiendo antes y después de la palabra a buscar el carácter especial $\backslash \mathrm{b}$ para indicar que la búsqueda debe ser sólo de palabras completas, y todo ello, con la opción IGNORECASE, para que encuentre las palabras independiente de si incluyen letras mayúsculas o minúsculas. Por ejemplo: si estamos contando el número de ocurrencias de la palabra "caja" no tendrá en cuenta "cajas", pero si "Caja". 
Finalmente, vamos almacenando en la variable text_csv el texto para la salida con los datos obtenidos y el formato adecuado separados por ";" que al final de todo el proceso es mandado al fichero out_file.csv.

1. \#!/usr/bin/env python3

2. from cStringIO import StringIO

3. from pdfminer.pdfinterp import PDFResourceManager, PDFPageInterpreter

4. from pdfminer.converter import TextConverter

5. from pdfminer.layout import LAParams

6. from pdfminer.pdfpage import PDFPage

7. import os

8. import sys

9. import re

10.

11. def convert(fname, pages $=$ None):

12. if not pages:

13. $\quad$ pagenums $=\operatorname{set}()$

14. else:

15. $\quad$ pagenums $=\operatorname{set}($ pages $)$

16.

17. $\quad$ output $=$ StringIO()

18. manager $=$ PDFResourceManager()

19. $\quad$ converter $=$ TextConverter $($ manager, output, laparams $=$ LAParams ()$)$

20. $\quad$ interpreter $=$ PDFPageInterpreter (manager, converter)

21.

22. $\quad$ infile $=$ file $($ fname,,$r b ')$

23. for page in PDFPage.get pages(infile, pagenums):

24. interpreter.process_page(page)

25. infile.close()

26. converter.close()

27. text $=$ output.getvalue ()

28. output.close

29. return text

30.

31.

32. def findWholeWord(w):

33. return re.compile( $\left(r^{\prime} \mid \mathrm{b}(\{0\}) \backslash \mathrm{b}^{\prime}\right.$.format(w), flags=re.IGNORECASE).findall 34.

35.

36. def getWordCount(data, word):

37. return len(findWholeWord(word)(data))

38.

39.

40. def main():

41. if len(sys.argv) !=4:

42. $\quad$ print('pdfwordcount files_file.txt words_file.txt out_file.csv')

43. $\quad$ exit(1) 
44

45. files_file $=$ sys.argv[1]

46. words_file $=$ sys.argv[2]

47. out_file $=$ sys.argv[3]

48.

49. $\quad \mathrm{ff}=$ open(files_file, $" \mathrm{r}$ ")

50. $\mathrm{fw}=$ open(words_file, $" \mathrm{r} "$ )

51. text_csv $=" "$

52.

53. for word in fw:

54. text_csv += ";" + word.replace("\n", "')

55. text_csv $+=" \backslash \mathrm{n} "$

56. fw.seek(0)

57.

58. for file in $\mathrm{ff}$ :

59. file = file.replace("' $\backslash n "$, "'")

60. file_= file.split(" ")

61. file $=$ file_[0]

62. pages $=$ None

63. text_csv $+=$ file

64. if len (file_) $==3$ :

65. $\mathrm{sp}=$ int(file_[1]) - 1;

66. ep =int(file_[2]);

67. pages $=$ range(sp,ep)

68. text_csv += "(" + str( $(\mathrm{sp}+1)+$ "-" + str(ep $)+$ ")"

69. $\quad$ text $=\overline{\text { convert(file,pages) }}$

70. for word in fw:

71. $\quad$ word = word.replace("' $1 \mathrm{n}$ ", "')

72.

73. \# check if the specified file exists or not

74. try:

75.

76.

77.

78.

79.

$$
\begin{aligned}
& \text { if os.path.exists(file): } \\
& \text { print("file " + file) }
\end{aligned}
$$

except OSError as err:

print(err.reason)

exit(1)

80. totalWords $=$ getWordCount(text, word)

81. print word + ": " $+\operatorname{str}$ (totalWords)

82.

83. text_csv $+="$;" $+\operatorname{str}($ totalWords)

84. text_csv $+=" \backslash n "$

85. fw.seek(0)

86. fo $=$ open(out_file, "w")

87. fo.write(text_csv.decode('utf8').encode('iso-8859-1'))

88.

89. fo.close() 
90.

91.

92. if name_ $=={ }^{\prime}$ main _':

93. main() 